plifier, a 3,000-volt rectifier and a. 10,000-volt rectifier. For telephone operation two more units are required, namely, a speech amplifier and a modulator. Voltage breakdown, which is an ever-present hazard due to the high voltages produced in radio equipment of this power, is minimized by adequately spacing and insulating all components, by avoiding sharp edges on metal parts, and by installing corona shields and horn gaps where applicable. Excessive temperatures are avoided by employing adequate current-carrying capacity in all conductors, ample radiating surfaces, water cooling, and forced air circulation by means of blowers.

Recent developments incorporated in this equipment include electronic keying with weight control, modulated carrier wave telegraphy by phase modulation, special type balancing network, multistrand filament tube, vacuum condensers. The article gives, at some length, details of the electrical design and the mechanical construction of the general assembly of the equipment and of the component parts which come broadly under the headings of controls, personnel protection, radio frequency driver unit, power amplifier unit, 3,000-volt rectifier unit and 10,000-volt rectifier unit. A table of specifications summarizes the more detailed equipment description.

\section{Optics Applied to Engineering}

A LeCture entitled "Optics Applied to Engineering" was delivered by Mr. K. J. Habell at a meeting of the Leicester Branch of the Association of Scientific Workers held on June 2 at the College of Technology, Leicester. Mr. Habell described the principles of several types of optical instruments now in increasing use in engineering workshops, and much interest was shown in those of the more difficult types of profile projection. The application of telecentric systems for the avoidance of magnification errors due to incorrect focusing and to ensure the imagery of the correct profile was very well illustrated by diagram. matic and experimental slides showing the images of a circular hole produced by convergent, divergent and collimated beams of light. Other instruments described included the tool-room microscope for the examination of form tools and screw-thread forms, and alignment telescopes for measuring the alignment and relative tilt of closely or widely separated bearings and jigs. Details were given of auto-collimating telescopes for high precision work in angular measurement. The importance to the war effort of instru ments of the types described was emphasized. A selection of the instruments was on view, and was demonstrated after the meeting.

\section{Chemical Engineering at Leeds}

The Department of Coal Gas and Fuel Industries (with Metallurgy) of the University of Leeds was established in 1906 to provide degree courses in fuel and metallurgy. In 1910 a fund was raised by the gas industry in order to perpetuate the memory of Sir George Livesey, the distinguished gas engineer, and this was allocated to endow the chair of the Department now known as the Livesey professorship. A degree course in gas engineering was instituted at that time. Since then the Livesey Advisory Committee, which is composed of representatives of the Institution of Gas Engineers, of the Society of British Gas Industries, and of the University, has had under consideration the need for extending the courses in order to keep pace with the growth of knowledge and the increasing demands of industry. In particular, for those passing into the constructional side of the gas industry and into the larger undertakings as well as to the staffs of chemical plant manufacturers generally, a broader training is necessary. On this account the Committee recently recommended the establishment of an alternative four-year course in chemical engineering, which has now been approved by the University; the new course will begin with the autumn term.

\section{Domestic Electricity Supply}

AN optional-control system of domestic electricity supply is described by P. Schiller (J. Inst. Elec. Eng., 89, Pt. 2, No. 9 ; June, 1942), which is designed to meet the objection often raised to domestic load control of any kind, in that it involves encroachment on the consumer's liberty to use his supply as he wishes. It is suggested in the paper that the consumer be given the opportunity at any moment and for any period of time readily to change over from a controlled to an uncontrolled supply, and vice versa, the consumption during periods in which the load control is made inoperative being charged at a higher price. The price change can be effected by a gear-change device in the kwh. register or in the prepayment mechanism of the meter, actuated in conjunction with the changeover in the operation of the load control. The necessary modification of apparatus and the extra cost entailed are both of a minor nature.

\section{Siting of Power Stations}

A Paper by F: Favell (J. Inst. Elec. Eng., 89, Pt. 2 , No. 9 ; June 1942), on the considerations to be given to this subject, points out that in recent years the siting of electricity-generating stations has tended to be affected increasingly by non-technical considerations such as legal requirements, amenities, etc. These considerations become of special importance when a particular scheme is submitted to a public inquiry by the Electricity Commissioners under Section II of the Electricity (Supply) Act, 1919. The paper records some of the issues to be borne in mind when siting power stations in Great Britain and at the same time it refers to some factors which have a bearing on power station construction irrespective of location. It is divided into two main parts, the first dealing with considerations arising out of parliamentary legislation, and the second with more technical and practical problems. The first part refers to the Town and Country Planning Act, 1932; the Coal Act, 1938 ; the Coal Mines Act, 1930 ; and various other statutory requirements. The second part deals with chimney emissions; sewage effluent for circulating water; amenities ; and alternative sites.

\section{Californian Fisheries}

THE report on the commercial fish catches of California for the year 1940 (State of California Department of Natural Resources. Division of Fish and Game. Bureau of Marine Fisheries. Fish Bulletin No. 58 ; 1942) makes available the summaries of commercial fish landings in each region of the State and also includes tables of numbers and nationality of the commereial fishermen and the number of boats of each type engaged in the fishery. A rapid development of the shark fishery is outstanding and is caused by the high price offered for liver oils of high vitamin A potency. This increase in the shark fishery, with 
intensive mackerel fishing and the large amount of sport fishing, has resulted in an increase of 950 boats in 1840-41 registrations over the previous year and is most noticeable in the group between $25 \mathrm{ft}$. and $39 \mathrm{ft}$. long. There has been a steady development of sport fishing in the ocean waters of Southern California, and the amount of small fish required as bait must be considered together with its effect on the severel species used as bait. The statistical records include not only the sport catoh itself but also the harvesting of the small-sized fishes used by the anglers for bait. Sardines and anchovies are the most important in the bait catch, comprising 98 per cent of the tatal, the fishes being $2 \frac{1}{2}-6$ in. long. A useful list of the common and scientific names of fishes, crustaceans and molluscs involved in the fisheries is given at the end of the report.

\section{Inter-American Friendship through the Schools}

THE U.S. Office of Education has issued as Bulletin No, 10, 1941, "Inter-American Friendship through the Schools", a report based upon a research study conducted by the Office of Education for the specific purpose of ascertaining the extent of inter-American studies that are already a part of the school curriculum. The bulletin is based largely on the replies of school administrators to a questionnaire, and the central purpose of the investigation was to discover the opportunities of learning which the curriculum presents and the patterns of teaching relative to the development of inter-American understanding that are to be found in the elementary and secondary schools of the United States. From the 6,623 adIministretors to whom the questionnaire was sent, 2,4.71 replies were received in time to be tabulated for the report, Of these, 671 stated that Spanish was being taught, and one half of the sehools reporting indicated that, although they did not offer Spanish, they provided a study of the other Americas in various courses given in English. No study relating to the other American republics in Spanish or in English was reported by $\mathbf{5 2 1}$ of the schools.

\section{Dinosaur Find at Washington, D.C.}

IT is stated by Science Service, of Washington, D.C., that the broken upper part of a saurian thigh. bone has been found in a new excavation being made for the D.C. filtration plant at Washington. The bone was identified as belonging to one of the sauropod group of dinosaurs by Dr. C. W. Cilmore, curator of vertebrate palæontology at the U.S. National Museum. Two finds of dinosaur bones have previously been made in Washington; they were of rather fragmentary fossils. Judging from the sixe of the present find, Dr. Gilmore said, the original animal was about ten feet high at the hips and fifty or sixty feet long, weighing approximately ten tons. Apparently, from the geological evidence, it was trapped in a small pond or mudhole and so perished. These creatures lived during the Cretaceous, about 150 million years ago.

\section{Restoration of Historic Monuments in the U.S.S.R.}

A sPECral committeo for the registration and protection of architectural relics and historic monuments has been set up by the Soviet Government. It consists of leading members of the Academy of Sciences and arehitects, headed by Igor Grabar, a Stalin prize- winner. One duty of this committee will be to establish the amount and nature of the deatruction and damage caused by the Germans in occupied districts and, where restoration is at all possible, to supervise the work.

\section{Cosmic Ray Research}

AN expedition of the Academy of Sciences of the U.S.S.R., led by Prof. A. I. Alikhanov, has arrived in Erevan, the capital of Soviet Armenia, to study cosmic rays. It will be in the field for about six weeks, making observations at the high-altitude meteorological station in the Alpaz mountains.

\section{Recent Earthquakes}

A SEVERE earthquake shook the towns of Santiago and Valparaiso and the region between the towns at about 1.30 a.m. (local time) on June 29. The Intendencia, headquarters of the Provincial Government, and other buildings were damaged in Valparaiso. Property was also damaged in Santiago, and for a while the electricity supply was interrupted. Thirty-seven people were reported injured. The earthquake was probably the most severe in Chile since 1927, when Talca and Concepcion were destroyed.

A moderate earthquake shook the town of Karachi at 8.30 a.m. approximately on the morning of July 3. No damage has been reported.

\section{Free German Institute in London}

A Free German Institute is being founded by the science section of the Free German I League of Culture in Great Britain. The airns of the Institute are : (i) to uphold and develop the valuable traditions of the Free German research work and teaching ; (ii) to provide for interchange of opinion between Free German men of science and those of the United Nations; (iii) to strengthen the German refugee youth in the spirit of intermational understanding, and to enable them to help in re-shaping Germany's cultural life after the destruction of Nazism. The opening session will be held on July 17 at 7.30 p.m. at the Everyman Theatre, when an address will be given by Dr. Joseph Needham. Further particulars of the movement can be obtained from the secretary, Free German League of Culture, 36 Upper Park Road, London, N.W.3.

\section{Announcements}

The honorary degree of D.Litt of the University of Oxford has been conferred on Commander Claude Schaeffer, of the Free French Navy, who is deputy curator of the Musée des Antiquités Nationales at Saint-Germain, and conducted important archæological excavations at Ras Shamra in North Syria.

A WhOLE-DAY conference is being arranged by the Nutrition Society, jointly with the Food Group of the Society of Chemical Industry, on "Dehydration of Foods and the Effect on their Nutritional Value", to be held at the British Medical Association House, London, on July 25. A later meeting, probably at the end of October, will deal with "Trace Elements in Nutrition". Further particulars of meetings can be had from the honorary secretary of the Nutrition Society, Dr. Leslie Harris, Nutritional Laboratory, Milton Road, Cambridge. 